\title{
An Analysis on Communication strategies Employed by Indonesian English as Foreign Language Adult Students
}

\author{
Mohamed Nizar, Putu Kerti Nitiasih, and Wayan Suarnajaya \\ English Education, Ganesha University of Education, Singaraja, Bali, Indonesia
}

\begin{abstract}
As an EFL country, English Language Teaching (ELT) in Indonesia should be more focused on developing students' strategy, particularly communication strategy (CS). The reason is because these students are triggered by instrumental motivation in learning English. However, awareness toward CS should also be possessed by teachers so they can develop students' CS through certain way. Unfortunately, it is rarely found English teacher who is aware about this notion. Thus, this study was conducted to provide data about initial CS of adult students in private university in Bali. According to experts, this age level has already got fully developed cognitive and linguistic capabilities. Thus, they are considered to be able to employ and use CS well. Through this study it is found that they possess 20 initial CSs out of 38 CSs from the referred taxonomy. The findings of this study could be beneficial for the development and novelty of future research concerning with CS and to enhance teachers' awareness toward CS, particularly the ones who establish private course offering intensive speaking program as well as for the lecturers in the concerned university.
\end{abstract}

Keywords: Communication Strategies, EFL, Adult Students, English Language Teaching.

\section{Introduction}

Strategy in language learning can be defined as actions or thoughts that a person uses in solving problems he/she encounters while learning or speaking in foreign language [1]. This strategy is divided into two divisions, 'Learning Strategy' and 'Communication Strategy' (CS) [1]. In relation to English language teaching, these strategies are equally important. However, considering the trends of English teaching nowadays is to develop communicative skills more [1], CS is the strategy that should be well mastered by students and those who are learning English, especially the ones living in EFL countries.

In educational context, awareness of CS, should not solely be possessed by students/ language learners. Teacher should also have a good mastery of it. By being mindful to students' CS, teacher could develop students' initial CS by implementing what is called Strategies-Based Instruction (SBI) in language learning. Experts states that strategy mastery, especially CS, could lead to autonomous learning [2]. Therefore, understanding 
and knowledge toward students' CS is really essential to be possessed by foreign language teachers so that they can their students' CS.

However, it is seldom found teachers that really pay well attention to this strategy. This normally occurs in countries in which English is taught as foreign language; for example Indonesia. Since English is taught as foreign language, students in Indonesia rarely speak English on regular basis in their daily activities. Teachers tend only to focus on developing students' competency according to the syllabus and curriculum. More specifically, in a private university in Indonesia, it is known that there are still found lectures who have insufficient knowledge about strategies used by language learners, including CS [3]. The main reason is because these teachers graduated from linguistics or literature department instead of teacher training and education program. Corresponding to the observation, similar matter also occurred in the university where the study took place. Based on the researcher's experience while doing teaching practice program in 2017, some of lecturers would prefer to develop students' speaking skill through other teaching methods instead of concerning on developing the students' initial CS. This fact is also supported by the statement of the students obtained from personal interview. Hence, some students of this private university were chosen as the subject of this study.

Besides, the reason why adult students were observed is because experts' descriptions on adult students imply that they are considered to be more able to use CS well. They are also considered to have a mature cognitive and linguistic ability and tend to use their prior knowledge to overcome problems while speaking in L2 [4]. Moreover, the reason why adult students learn L2 in Indonesia as EFL country is mostly based on instrumental motivation (i.e. to be able to study or to work abroad or at least to get a job in English fields to get considerable salary). Pertaining to the instrumental motivation, good communication skill is needed for every job provider certainly needs employees who have good communication skills. Thus, CS of these adult students is really important to develop.

In order to develop students' CS, teachers should definitely identify them first. This study was conducted to provide data regarding to students' initial CS to develop and recommendation for the concerned teachers to implement method or teaching technique to develop students' CS. It is expected that the findings could be beneficial and could enhance teachers' awareness toward students' CS especially for teachers who are not majored from teacher training and education.

\section{Methods}

The research was conducted in the form of qualitative design. Judgment sampling was applied in determining the sample of this study. There were 16 ( 8 males $\& 8$ females) $6^{\text {th }}$ semester students majoring in teacher training and English education in Mahasaraswati university, Bali, Indonesia. These students age 20 to 21 years old. In addition, in this study data were collected through Documents or artifacts analysis, Observation and Interview. This study also involve some instruments as data collection tools such as: the researcher himself as the main instrument, observation sheets, video recorder, interview guide and an interactive oral production task: role play instruction. Pertaining to role play instruction, students were basically required to perform speaking performance in which they were told to pretend as a tour guide or tourists visiting a certain place for approximately three and half minutes. Students, pretending as tour guide and tourist, were then told to explain and to have conversation related to things representing Hinduism in Bali and Balinese cultures. Their performances were recorded and were later analyzed.

Technically the recordings were transcribed and every CS found was coded and classified based on CS taxonomy proposed by Dörnyei \& Scott [5]. There are 41 types of CS based on the taxonomy, they are as follows: Message Abandonment (1), Message 
Reduction (Topic Avoidance) (2), Message replacement (3), Circumlocution (paraphrase) (4), Approximation (5), Use all of purpose words (6), Word coinage (7), Restructuring (8), Literal translation (transfer) (9), Foreignizing (10), Code switching (language switching) (11), Use of similar sounding words (12), Mumbling (13), Omission (14), Retrieval (15), Self-repair (16), Other-repair (17), Self rephrasing (18), Over-explicitness (waffling) (19), Mime (nonlinguistic/ paralinguistic strategies) (20), Use of fillers (21), Self-repetition (22), Other-repetition (23), Feigning understanding (24), Verbal strategy makers (25), Direct appeal for help (26), Indirect appeal for help (27), Asking for repetition (28), Asking for clarification (29), Asking for confirmation (30), Guessing (31), Expressing nonunderstanding (32), Interpretive summary (33), Comprehension check (34), Own-accuracy check (35), Response: repeat (36), Response: repair (37), Response: rephrase (38), Response: expand (39), Response: confirm (40), Response: reject (41). Once classification is done, conclusions were then drawn by previously matching the obtained data with the related books (theoretically) as well as with the related findings from similar researches.

\section{Findings and Discussions}

Based on the observation, adult students are known to consistently employ 20 of 41 types of communication strategies referred. They are Use of fillers (21), Self-repetition (22), Retrieval (15), Mime [the use of non-linguistic act] (20), Self-repair (16), Indirect appeal for help (27), Code switching (11), Mumbling (13), Circumlocution (paraphrase) (4), Message abandonment (1), Restructuring (8), Asking for confirmation (30), Approximation (5), Expressing non-understanding (32), Asking for repetition (28), Selfrephrasing (18), Other-Repetition (23), Own-accuracy check (35), Message reduction [topic avoidance] (2) and Omission (14). For more detailed display as well as to ease understanding the explanation, Table 1 is provided below.

Table. 1. Communication strategies consistently employed by adult students

\begin{tabular}{|c|c|c|c|c|}
\hline \multirow{2}{*}{$\begin{array}{l}\text { CS } \\
\text { consistently } \\
\text { employed }\end{array}$} & \multicolumn{2}{|c|}{$\begin{array}{c}\text { Frequency of the employed CS in each } \\
\text { performance }\end{array}$} & \multicolumn{2}{|c|}{$\begin{array}{l}\text { Number of students employing the CS } \\
\text { in each performance }\end{array}$} \\
\hline & $1^{\text {st }}$ performance & $2^{\text {nd }}$ performance & $1^{\text {st }}$ performance & $2^{\text {nd }}$ performance \\
\hline$(21)$ & 567 & 571 & 16 & 16 \\
\hline (22) & 43 & 45 & 12 & 14 \\
\hline (15) & 61 & 48 & 13 & 13 \\
\hline (20) & 9 & 21 & 8 & 9 \\
\hline (16) & 16 & 17 & 10 & 12 \\
\hline (27) & 25 & 17 & 12 & 7 \\
\hline (11) & 3 & 10 & 3 & 5 \\
\hline (13) & 7 & 9 & 5 & 7 \\
\hline (4) & 3 & 7 & 2 & 3 \\
\hline (1) & 3 & 7 & 3 & 6 \\
\hline (8) & 4 & 6 & 4 & 5 \\
\hline (30) & 10 & 6 & 8 & 6 \\
\hline$(5)$ & 1 & 5 & 1 & 3 \\
\hline (32) & 5 & 4 & 4 & 4 \\
\hline (28) & 1 & 3 & 1 & 3 \\
\hline (18) & 1 & 2 & 1 & 2 \\
\hline (23) & 4 & 2 & 3 & 2 \\
\hline (35) & 1 & 2 & 1 & 2 \\
\hline (2) & 1 & 1 & 1 & 1 \\
\hline (14) & 1 & 1 & 1 & 1 \\
\hline
\end{tabular}


Pertaining to the use of CS no. 21 (use of filler), students tend to say "aah", "umm" or extend certain words as the filler to gain time for thinking what to say next; for example, student no. 9 said,"...before aah(21) ceremony nyepi nyepi and we doo(21) tooo(21) goo(21) aah(21) to go the beach ..." (Selected from the transcription of adult student no. 9).

In employing CS no. 22 (Self-repetition), students tend to repeat words they previously pronounced to gain time for thinking what to say next; for example, student no. 1 said, "...before aah(21) nyepi day we we we do(22) a parade..." (Selected from the transcription of adult student no. 1).

The use of CS no 15 (Retrieval) is dominated by series of incomplete or wrong forms or structures (sentences or words) that are pronounced before reaching the optimal form; for example "...will be held for the tena' teenager(15) so the teenager will..." (Selected from the transcription of adult student no. 2).

Furthermore, the form of CS no. 20 (Mime [the use of non-linguistic act]) employed by these students was kind of visual description using hands; for example "...do you know drum? Drum? (*exemplifying drum with his hands)(20)..." (Selected from the transcription of adult student no. 6).

Next, the use of self-repair as CS no. 16 is dominated by self-initiated corrections of errors made by the student when they spoke; for example, "...popular name nyepi is $\underline{\text { aah(21) }}$ silent way eh silent day(16)." (Selected from the transcription of adult student no. 12).

In relation to the use of CS no. 27 (Indirect appeal for help), adult students are more likely overcome their L2 inaptitude by asking for help from the interlocutor indirectly through face expression and eye contact; for example, student no. 14 said, “...and a' red for brahma and purple for aah(21) (*appeal for help by making an eye contact)(27) aah(21) siwa (Shiva)..." (Selected from the transcription of adult student no. 14).

The following strategy employed by the students is CS no. 11, Code switching. These students simply use either L1 or L3 words or phrase in their L2 speech once they had no idea what to say; for example, student no. 2, “...will cut your point(5) (*pointing to his front teeth)(20) or gigi seri (incisor)(11)..." (Selected from the transcription of adult student no. 2).

Another CS employed by the students to gain time for thinking what to say next is CS no. 13, Mumbling. Once they stuck in the middle of their speech, some students occasionally construct what they want to say correctly by muttering inaudibly; for example, student no. 15 said, "... aand(21) aand(21) rice paddies okay so $\underline{\text { (*paused for some seconds }}$ mumbling)(13) usually wee(21)..." (Selected from the transcription of adult student no. $15)$.

Some of adult students were also known to employ Circumlocution (paraphrase) or CS no. 4 in which they give illustration, description or example of certain objects in overcoming their L2 inaptitude; for example, student no. 16 said, “...how we make it? we use semat. Semat is very small thing (*describing it with his hands) and that is made from bamboo(4)..." (Selected from the transcription of adult student no. 16).

On the other hand, the form of CS no. 1 (Message abandonment) is dominated with messages which is intentionally left unfinished due to L2 inaptitude, for example, student no. 13 said, "...we will burn our body aah until mmm and our body will back into the nature(1)..." (Selected from the transcription of adult student no. 13).

Furthermore, Restructuring (CS no. 8) is a kind of CS in which the speaker abandons the executions of verbal plan and substitutes it with other alternative plan instead due to L2 inadequacy. This is one of many examples of this CS employed by student no. 13, "That's all aah about ngaben and thank you for, thank you very much and have a nice day(8)" (Selected from the transcription of adult student no. 13). 
Additionally, in employing Asking for confirmation (CS no. 30) adult students tend to be kind of confirmation statement or question to assure that one heard or understood something correctly; for example, (Student 4 asked a question, “Aah(21) okay I would like to ask about aah(21) how about if we don't a' don't do it?(15)) (*Student 8 confirmed the question by whispering)(30) (Selected from the transcription of adult student no. 8).

Other strategy used by adult students is Approximation (CS no. 5). Its form is a kind of single alternative lexical items (e.g. superordinate or related terms) which share semantic features with the target word in L2 speech; for example, student no. 9 said, "...function in melasti is aah(21) aah(21) foor(21) for the Balinese people(15) aah(21) a' clear body (*laughing feeling embarrassed) clear your body $(5) . . . "$ (Selected from the transcription of adult student no. 9).

Furthermore, the form of Expressing non-understanding (CS no. 32) that mostly employed by the students is a kind of re-explanation request through face expression; for example, (*a female student asked a question, "*speaking in Japanese* aah(21) could you tell me umm(21) aah(21) only woman that can do the baleganjur or not? *student 6 was frowning*(32)..." (Selected from the transcription of adult student no. 6).

Referring to the use CS no. 28, Asking for repetition, adult students tend to use the regular phrase such as "pardon" or simple repetition request; for example, (*Student 16 asked a question, "okay my name is made *the mic. is screaming* check my name is Made and I'm froom(21) California, aand(21) is that just something like traditional drum or anyone else umm(21) to go with baleganjur?) *"pardon me?", student 6 asked for repetition*(28)..." (Selected from the transcription of adult student no. 6).

In addition, Self-rephrasing (CS no. 18) can be described as a paraphrase of either sentence or word previously said to make clear the intended meaning. Here is one of the examples of this strategy employed by student no. 11, “...I think lawar aah spicy or not its depend aah of what consume it I think I think its depend on who want to eat(18)..." (Selected from the transcription of adult student no. 11).

Other-Repetition (CS no. 23) is other CS which is also employed to gain time to think. Its form can be a repetition of what the interlocutor said; for example, $(*$ Student 10 asked a question, " $\mathrm{mmm(21)}$ my name is Ogek from Singapore aah(21) I wanna ask you a' how many times aah(21) do the melasti?") "okay how many times(23), the first is..., Student 4 answered" (Selected from the transcription of adult student no. 4).

Own-accuracy check (CS no. 35), as the other initial CS possessed by adult students, can be described as a strategy in which the speaker check that what him/herself said was correct by asking a concrete question to the interlocutor or repeating a word with a question intonation. Here is example of it selected from the transcription of adult student no. 16, "Student 16 said, “...we don't have pen or pencil yet in the past so we use kind of very $\underline{\operatorname{aah}(21)}$ shave (*his voice raising when saying 'shave' as if he is checking his accuracy $(35) \ldots$,

The last, there are $2 \mathrm{CSs}$ which were equally employed for 1 time in both performance. They are namely Message reduction [topic avoidance] (CS no. 2) \& Omission (CS no. 14). The form of the former one is kind reduced message due to L2 inaptitude, here is the example as selected from the transcription of adult student no. 11, student no. 11 said, “...I think lawar just can aah(21) consume just for aah(21) one day (*paused for a second) one day(2)..." (*She was actually about to proceed but canceled it because it will lead to aspecific topic she couldn't tell well). on the other hand, the form of the latter one, omission, is exactly the same as described in the taxonomy; here is the example as selected from the transcription of adult student no. 6, student no. 6 said "...That's $\underline{\operatorname{aah}(21)}$ that's

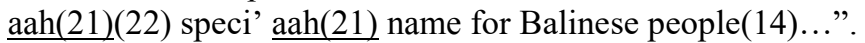

Before making a conclusion, these findings were compared to findings of similar researches $[6,7,8,9,10]$ which are conducted in other EFL countries. It is found that adult 
students in EFL countries tend to employ similar CSs, especially the use of Mime [the use of non-linguistic act], code switching, Approximation, Asking for confirmation, circumlocution, and appeal for help.

\section{Conclusions}

There are two conclusions in relation to the findings of this study. Firstly, adult students in EFL countries are known to employ similar CSs to cope with their L2 inadequacy. Secondly, CSs identified in this study attest the maturity of cognitive and linguistic ability of adult students in overcoming problems while speaking in L2 as stated by referred expert [4]. These CSs, especially use of fillers (21) and Message reduction [topic avoidance] (2), are students' good assets to develop as it reveals capability to provide sense of security for themselves so that they can do sort of maneuver to help them deal with difficulties in delivering message just like what expert says [11]. It is expected that these findings could be beneficial for the development of future research concerning with CS and to enhance teachers' awareness toward CS, particularly the ones who establish private course with intensive speaking program as well as for the lecturers in the concerned university so that they can develop students CS through SBI or other ways.

I would like to express my full gratitude to The Almighty God "Ar-rahmaan Allah Subhanahu Wa Ta'ala" for His blessings to fininsh this article. Furthermore I would like to address my sincere appreciation to my beloved family, Abah, Mama, Faisal and Ira, for their total support. At last, I would like to address my gratitude and appreciation to my principal supervisor Prof. Dr. Putu Kerti Nitiasih, M.A. and my second supervisor Drs. I Wayan Suarnajaya, M.A., Ph.D., whose patience, expertise, motivation and gentle guidance have helped me to finish this article well.

\section{References}

1. H.D. Brown, Principles of Language Learning and Teaching (fifth Edition), (New York: Pearson Education, 2007)

2. A.L. Wenden, TESOL Newsletter, 19, 1-7 (1985)

3. S. Wahyuni, L2 Speaking Strategies Employed By Indonesian EFL Tertiary Students across Proficiency And Gender, (Canberra: University of Canberra, 2013).

4. A.F.V. Smith, G. Strong, Adult Language Learners: Context and Innovation (Maryland: TESOL Publications, 2009)

5. Z. Dornyei, M.L. Scott, Communication Strategies in a Second Language: Definition and Taxonomies. LL., 47, 173-210 (1997)

6. C.A.R. Cervantes, R.R. Rodriguez, Gist: Edu. n. L. Rsrch. J, 6, 111-128 (2012)

7. Ş. Yaman, P. Irgin, M. Kavasoğlu, JESR. 3, 255-268 (2013)

8. R.A.A. Alawi, PJEL, 2, 1-11 (2016)

9. N.T. Thu, N.T.K. Thu, AERJ, 4, 283-287 (2016)

10. R.L. Ugla, N.I. Adnan, M.J.Z. Abidin, IJERE, 2, 44-50 (2013)

11. Z. Dornyei, On the Teachability of Communication Strategies. TQ, 29, 55-85 (1997) 